\title{
Product Design of Semi Flexible Screw Conveyor
}

\author{
Santanu Chakarborthy ${ }^{1}$, Anshuman Mehta $^{2}$ \\ ${ }^{1}$ (Assistant Professor, Department of Mechanical Engineering, Sikkim Manipal Institute of Technology, India) \\ ${ }^{2}$ (UG Student, Department of Mechanical Engineering, Sikkim Manipal Institute of Technology, India)
}

\begin{abstract}
In this project we have endeavoured to study and create an adaptive design of semi-flexible screw conveyor using conventional specifications and standards. A CAD model shall be developed of a three segment screw conveyor that can function as a single unit as well as independently and also can be mix matched, thus providing flexibility by length variation. Also applying the concept of universal joint, each of these segments can be linked at an angle, both in the horizontal and vertical planes thus providing flexibility by angle variation. The successful design and assembly of the CAD model shall provide us a cheap, efficient and standard method of providing flexibility in screw conveyors.
\end{abstract}

Keywords: Auger Section; Keys and Splines; Norelem Single Cardan Joint; Trough; Tonnage Capacity

\subsection{Theory}

\section{Introduction}

The screw conveyor is one of the oldest methods of conveying materials known to mankind with the original design dating back to more than two thousand years. The first type of screw conveyor was the Archimedes' screw, used since ancient times to pump irrigation water.

A screw conveyor mechanism consists of a rotating helical screw blade, called a "flighting", usually within a tube, to move liquid or granular materials. They are used in many bulk handling industries. Since the screw conveyor came into general use a little over a century ago for moving grains, fine coal and other bulk material of the times, it has come to occupy a unique place in a growing area of material handling processing. Today, modern technology has made the screw conveyor one of the most efficient and economical methods of moving bulk material.

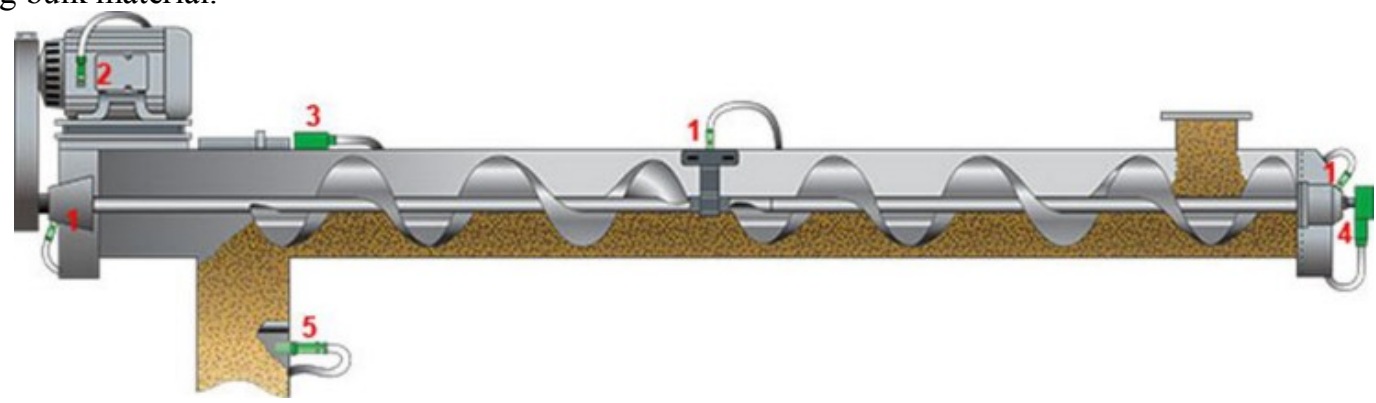

Figure 1.1 Screw Conveyor

The working principle of the Screw Conveyor is based on same principle as the Archimedes Screw that was used in ancient times in Greece and Egypt to draw water for irrigation purposes or to drain water from low lying mining areas. Archimedes' screw consists of a screw (a helical surface surrounding a central cylindrical shaft) inside a hollow pipe. The screw is turned usually by a windmill or by manual labour. As the shaft turns, the bottom end scoops up a volume of water. This water will slide up in the spiral tube, until it finally pours out from the top of the tube and feeds the irrigation systems.

The basic transport mechanism is that the material resting between two adjacent screw flights on the same axis is promoted to slip down the face of the 'rising' side of the flight as the screw rotates. This action moves the product forward at the rate of one pitch per rotation of the screw, provided the material does not spill over the centre shaft to fall back into the proceeding pitch space as when the cross-sectional loading exceeds the height of the centre tube or the machine axis is excessively inclined.

Screw conveyors are but one class of screw type solids handling device, albeit a major form in industrial applications. Other types of helical screw-based solids handling machines are commonly described as 'screw feeders', 'screw elevators', 'hopper discharge screws' and 'metering screws'. Many forms of processing operations also utilise helical screws in their composition and many of the features described will equally apply to their operating circumstances. 


\subsection{Need}

As stated above Screw Conveyors are used in a variety of situations. Some of this situations require material to be transported over a large distance or at considerable heights. The path from receiving point to delivery point may not always be a straight one or even a constant one. Depending upon the material to be transported, or the storage capacity of the bins, the screw conveyor may need to be adjusted.

For example when storing grains in a silo, considerable energy can be saved if the grains are first conveyed up to a minimum height and then the conveyor is adjusted to deliver up to a greater height. Similar, in construction sites, when material is conveyed to fill structures for pillars etc., a huge amount of power consumption can be avoid by conveying in segmented heights by using a flexible conveyor.

\subsection{Concepts Available}

Till date various concepts have been developed to satisfy the need of a flexible screw conveyor. Like some of the few below. In April 1958, Inventors Marion H Fennimore and Ivan J Stephenson invented a Flexible Screw Auger ${ }^{[6]}$ for Conveying grain. Fig.1.2, in handling bulk materials such as grain and the like, screw or auger conveyors are frequently used. However, in certain circumstances there is no open path between the point where the material is located, and the point to which it is to be transported. In such circumstances normal screw conveyors cannot be used. It is the principal purpose of this invention to provide a flexible screw conveyor which may be bent around, over, or under obstacles existing in the path of transportation. A further purpose of the invention is to provide such a device having a plurality of universally connected short auger sections inserted in a flexible tube and rotatable supported therein, whereby to provide for substantial flexibility without impairment of conveying ability. More specifically the invention consists in making a portable bendable screw conveyor system by connecting a plurality of short screw conveyor or auger sections end to end by universal joint members which themselves include auger portions, providing open cage supports for the individual sections, which supports have bearings for the screw sections so that each support is free to turn with respect to an endwise adjacent support on the same axis that the screw section rotates, the supports being combined in a relatively stiff flexible tube by friction only, whereby the several supports may adjust themselves in bending of the tube to get around obstructions. The nature and advantages of the invention will appear more clearly from the following description and the accompanying drawings wherein a preferred form of the invention is shown. It should be understood, however, that the description and drawings are illustrative only, and are not intended to limit the invention except insofar as it is limited by the claims.

\section{In Figure 1.2:}

Figure 1 is an elevated view or the invention with a portion of the tube broken away; Figure 2 is an enlarged sectional view taken on the line 2-2 of Figure 1; Figure 3 is an enlarged sectional view taken on the line 3-3'of Figure 1; Figure 4 is an enlarged sectional view taken on the line d of Figure 1; and Y Figure. 5 is a perspective view of one of the 4 universal joint members, illustrating the spiral in thereon. Referring now to the drawings, the invention as shown. Figure 1, provides a portable flexible screw or auger type conveyor generally indicated at 10, which may be bent as desired to travel around corners and over obstacles in order to carry bulk materials from one place to another.

The conveyor comprises a plurality of short auger sections 11, each of which is composed of a drive shaft 12 with a helical auger blade 13 fixed thereto. As shown in Figure 1, the shaft 12 extends outwardly at each end beyond the ends of the blade 13. Bearing members 14 are rotatable mounted on the shaft 11 . At each end of the blade 13. Each of the bearing members 14 has a plurality of radial rods 15 secured thereto. The rods 15 extend outwardly and are slightly longer than the radius of the auger 11 . The radial rods 151 at each end of the auger section 11 are connected by longitudinal rods 16 which are equally spaced around the circumference of the auger 11 . The rods 15 and 16 together with the bearings 14 comprise a cage surrounding each auger section 11 , and supporting it for free rotation therein. As hereinbefore described, there are a plurality of the auger sections 11 . Each of these sections 11 and their surrounding cages of rods 15 and 16, are placed end to end. 


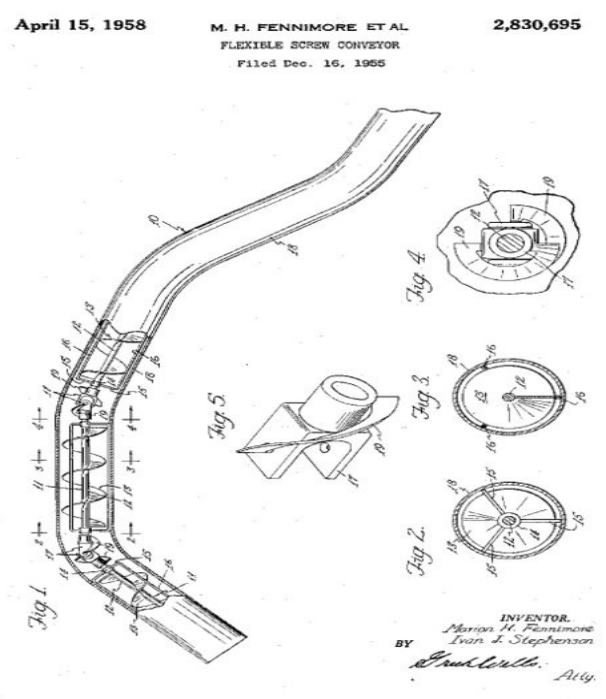

Figure 1.2: Semi Flexible Screw Conveyor by Fennimore and Stephenson

The adjacent ends of the shafts 12 extending beyond the bearings 14 are fitted with short universal joint members 17 such as the one shown in Figure 5. The universal joint members 17 are attached together in the usual manner to provide for transmission of rotational power from one section 11 to the next. Power is supplied to the series of connected sections 11 by a motor or other power supply means (not shown) to the section 11 at either end of the series. A semi-flexible tube 18 is provided around the auger sections 11 as shown in Figures 1, 2 and 3. The tube 18 may be made of any suitable semi-flexible material that will hold its circular shape. It may be a flexible metal pipe, of construction similar to the well-known electrical conduit material, which is made of a strip of metal wound spirally with adjacent spirals inter-engaged.

As shown in Figure 1, a considerable space exists between each of the auger sections 11 within the tube 18. Due to the pressure of material being fed by the auger section 11 immediately behind each of these intermediate spaces, the material being conveyed will be forced into engagement with the next auger section 11 so that the spaces do not entirely defeat the operation of the conveyor 10 . However, these spaces will cause a slowing down and piling up of the 'material, and will hamper the operation to some extent. In order to reduce this tendency to a minimum, each of the universal joint members 17 is provided with a spiral in 19 which will, when the member 17 is rotated, propel the material being conveyed through the intermediate space between the sections 11. These is 19, best shown in Figures 4 and 5, are strips of metal bent into a spiral form and fixed onto the universal joint members 17, as shown. The fin 19 substantially encompasses the space from the trunnion pivots to the attaching end of the member 17.

As shown in Figure 1, the bending of the conveyor 10 occurs adjacent the universal joint members 17. When the conveyor 10 is bent, the members 17 shift toward the outside of the tube bend, because the tube curves and the members 17 pivot about their trunnion ends. In order to permit substantial deflection of the conveyor without rubbing the walls of the tube 13, the spiral tins 19 on the universal joint members 17 must be only about one-half as wide radially as the helical blades 13 .

The auger sections 11 are prevented from moving out of concentric alignment with the tube $1 \mathrm{~S}$, and are supported within the tube 18 by the cages formed of the rods 15 and 16. As shown in Figures 2 and 3, the longitudinal rods 16 engage 4the tube 18 to properly position the auger sections 11 . The rods 16 are not, however, fixed to the tube $1 \mathrm{~S}$ in any way and may slide endwise within the tube 13 to expose the auger sections 11 when repairs are needed. Also, since it is sometimes desirable to clean the conveyor to prepare for handling a different type of material, the auger sections 11 maybe pulled from the tube 18 for easy access.

One of the most difficult problems encountered with conveyors having flexible sections therein is that of bunching or folding of the flexible tubing at the inside of a bend. Such folding4 tends to restrict the flow of material within the tube. With the construction just described, this problem has been substantially overcome. Since the rods 16 are not fixed with respect to the tube 18, and since the whole length of the tube is of flexible material, the bunching or folding of the tube is substantially overcome. When bending occurs, the portion of the tube wall at the inside of the bend which normally resides between two auger sections 11 is not required to remain between the sections upon bending. Since the rods 16 may move endwise in the tube 18, those rods 16 on adjacent sections 11 which approach each other may slide in the tube slightly, instead of bunching the tube between them. 


\subsection{Concept Applied}

The angle of the blade to the horizontal must be greater than the angle of slip of the media on the flight face for this motion to occur. It is also clear that the dynamic repose condition attained by the moving media determines the transfer capacity of a given screw geometry. With a non-viscous liquid, such as water, surface slip will occur at a very shallow angle and, for screw that is rotating slowly, the surface profile will be virtually horizontal. Inclination of the screw axis therefore allows a free-flowing liquid to be elevated by inclining the screw axis but the axial transfer capacity reduces with inclination because the reduction in effective flight face inclination reduces the volume of the pocket of liquid that can be held between the flight pitches before spilling back over the centre shaft.

For our product model we have chosen to develop a Screw Conveyor model with three stages connected by universal joints. The universal joint allows power transmission at deflected angle in turn allowing each stage of the conveyor a certain degree of flexibility.

A screw conveyor will handle material up gentle inclinations with only a small loss of transfer capacity, provided the material is not in a fluid condition. However, the ability to elevate loose solids in a conventional conveying mode falls off progressively as the inclination is increased above $15^{\circ}$ to the horizontal, such that it will only move about $30 \%$ of its horizontal capacity when used at a shaft inclination of $30^{\circ}$ and above this angle of slope the conveying rate reduces very rapidly to zero.

Keeping this in mind we have selected the inclination of the 2nd and 3rd stage segments of the screw conveyor arbitrarily at $5^{\circ}$ and $10^{\circ}$ from the horizontal axis respectively. Arbitrarily we have also chosen the length of each segment as:

$\mathrm{L}_{1}=1500 \mathrm{~mm}$
$\mathrm{~L}_{2}=1000 \mathrm{~mm}$
$\mathrm{~L}_{3}=500 \mathrm{~mm}$

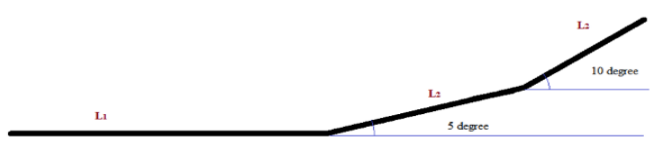

Figure 1.3 Inclination of each segment

\subsection{Recommended Dimensions of Screw Conveyor}

\section{Design Specifications Of Screw Conveyor}

Indian standard specification IS: $5563: 1985^{[1]}$ has specified the standard dimensions for all above components. The recommended dimensions as per above IS is given in Table $2.1^{[1]}$. The notations used in the table are shown in Fig. 2.1 Value of screw pitch generally varies from 0.8 to 1.0 times diameter D of the screw.
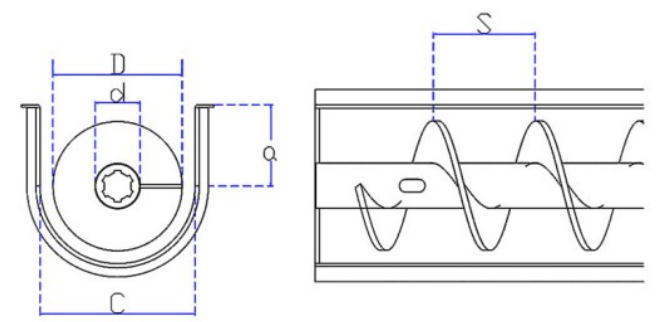

Figure 2.1 Screw Conveyor Dimensions

The selection of size of a screw conveyor basically depends on two factors ${ }^{[1]}$.

(i) The conveying capacity required and

(ii) Lump size of the materials to be conveyed.

The lump size of materials determines the minimum size of the screw diameter ' $\mathrm{D}$ ' to be chosen. $\mathrm{D}$ is recommended to be at least 12 times the lump size of a sized material or at least 4 times the largest lumps of an un-sized material.

The material to be conveyed is free flowing, mildly abrasive dry sand. As the lump size of dry sand is very, very small, a nominal diameter (D) of $100 \mathrm{~mm}$ helical screw shall be adequate for our purpose. The 
conveying capacity is left to be calculated upon a standard permissible speed (R.P.M)

The selected dimensions are:

a) Nominal Diameter of the helical screw $\mathrm{D}=100 \mathrm{~mm}$

b) Pitch of the screw $\mathrm{S}=80 \mathrm{~mm}$

c) Diameter of the screw shaft $\mathrm{D}_{1}=35 \mathrm{~mm}$

d) Width of trough determining gap between screw and trough $\mathrm{C}=120 \mathrm{~mm}$

e) Trough height from centre of screw shaft $a=63 \mathrm{~mm}$

f) Thickness of trough material $\mathrm{t}_{1}=2 \mathrm{~mm}$

g) Nominal thickness of screw flight $\mathrm{t}_{2}=5 \mathrm{~mm}$

\begin{tabular}{|c|c|c|c|c|c|c|c|c|}
\hline \multirow{3}{*}{$\begin{array}{l}\text { Nomina } \\
1 \text { Size D }\end{array}$} & \multirow{3}{*}{$\begin{array}{l}\text { Trough height } \\
\text { from center of } \\
\text { screw shaft to } \\
\text { upper edge of } \\
\text { the trough (a) }\end{array}$} & \multirow{3}{*}{$\begin{array}{l}\text { Trough } \\
\text { Width C }\end{array}$} & \multirow{2}{*}{\multicolumn{2}{|c|}{ Thickness Trough }} & \multirow{3}{*}{$\begin{array}{l}\text { Tubular Shaft } \\
\text { D } \times \text { Thickness }\end{array}$} & \multirow{3}{*}{$\begin{array}{l}\text { Coupling Shaft } \\
\text { Diameter }\end{array}$} & \multirow{2}{*}{\multicolumn{2}{|c|}{$\begin{array}{l}\text { Nominal thickness } \\
\text { of helical screws } \\
\text { Continuous Root }\end{array}$}} \\
\hline & & & & & & & & \\
\hline & & & $\begin{array}{l}\text { Medium } \\
\text { Duty }\end{array}$ & $\begin{array}{l}\text { Light } \\
\text { Duty }\end{array}$ & & & Medium & Light \\
\hline 125 & 75 & 120 & 2.0 & 1.6 & $33.7 \times 2.5$ & 25 & 5.0 & 3.15 \\
\hline 160 & 90 & 145 & 2.0 & 1.6 & $33.7 \times 2.5$ & 25 & 5.0 & 3.15 \\
\hline 200 & 112 & 180 & 3.15 & 1.6 & $42.4 \times 2.5$ & 40 & 5.0 & 3.15 \\
\hline 250 & 140 & 220 & 3.15 & 2.0 & $48.3 \times 3.5$ & 40 & 5.0 & 3.15 \\
\hline 315 & 180 & 270 & 3.15 & 2.0 & $60.3 \times 4.0$ & 50 & 7.0 & 5.0 \\
\hline 400 & 224 & 335 & 3.15 & -- & $76.1 \times 5.0$ & 50 & 7.0 & 5.0 \\
\hline 400 & 224 & 420 & 3.15 & - & $76.1 \times 5.0$ & 75 & 10.0 & 7.0 \\
\hline 500 & 280 & 420 & 3.15 & - & $88.9 \times 5.0$ & 75 & 10.0 & 7.0 \\
\hline 500 & 280 & 530 & 3.15 & -- & $88.9 \times 5.0$ & 75 & - & -- \\
\hline 630 & 355 & 530 & 3.15 & - & $114.3 \times 5.5$ & 75 & - & - \\
\hline 630 & 355 & 660 & 5.0 & - & $114.3 \times 5.5$ & 100 & - & - \\
\hline 800 & 450 & 660 & 5.0 & -- & $139.7 \times 6.0$ & 100 & -- & -- \\
\hline
\end{tabular}

\subsection{Recommended Dimensions of Splines}

Keys and splines are used to transmit torque from the drive shaft to the driven. A key is a feature that assembles with a keyway (or slot) on a cylindrical feature (shaft). A spline is a series of grooves cut along the length of a shaft (usually for a short length of the shaft). The spline assembles with "internal" splines on a mating hole, and the spline allows torque power to be transferred between the two components.

IS: $2327-1963^{[5]}$ lays down dimensions, in millimeters, of straight-sided splines for cylindrical shafts with internal centering, light series and medium series. The nominal dimensions common to shaft and hub, d, D and $\mathrm{B}$ are given in Table $2.2^{[5]}$ and the notations used are specified in Figure 2.2

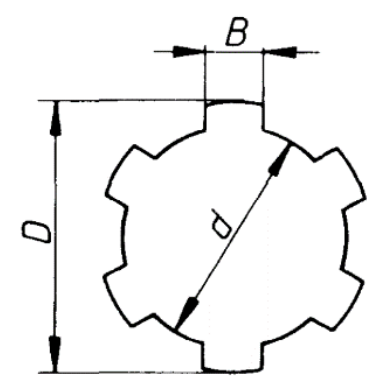

Figure 2.2 Straight Sided Splines

The engaged length of the spline can be derived from the maximum torque to be transmitted using the following equation ${ }^{[5]}$ :

$\mathrm{T}=\frac{1}{2} p_{b} \mathrm{hlN}(\mathrm{D}-\mathrm{h})$

Where,

$\mathrm{D}$ is the diameter of the shaft in $\mathrm{mm}$

$\mathrm{h}$ is height of the spline in $\mathrm{mm}$

$\mathrm{p}_{\mathrm{b}}$ is the allowable bearing pressure, $\mathrm{MN} / \mathrm{m}^{2}$

$\mathrm{p}_{\mathrm{b}}=7 \mathrm{MN} / \mathrm{m}^{2}$ for sliding fit

$\mathrm{N}$ is the number of splines

1 is engaged length of each spline 


\begin{tabular}{|c|c|c|c|c|c|c|c|c|c|c|}
\hline \multicolumn{11}{|c|}{ Table 2.2 Straight Sided Splines - Medium Duty Series } \\
\hline $\begin{array}{l}\text { Nominal size } \\
\text { NxdxD }\end{array}$ & $\begin{array}{ll}\text { No. } & \text { of } \\
\text { splines }\end{array}$ & $\begin{array}{l}\text { Minor dia. } \\
\text { d }\end{array}$ & $\begin{array}{l}\text { Major Dia. } \\
\text { D }\end{array}$ & $\begin{array}{l}\text { Width } \\
\text { B }\end{array}$ & $\begin{array}{l}\text { d1* } \\
\text { Min }\end{array}$ & $\mathrm{e}^{*} \operatorname{Max}$ & $\mathrm{f} *$ & $\begin{array}{l}\mathrm{g} \\
\text { Max }\end{array}$ & $\begin{array}{l}\mathrm{k} \\
\mathrm{Max}\end{array}$ & $\begin{array}{l}\mathrm{r} \\
\mathrm{Max}\end{array}$ \\
\hline $6 \times 11 \times 14$ & 6 & 11 & 14 & 3 & 9.9 & 1.55 & - & 0.3 & 0.3 & 0.2 \\
\hline $6 \times 13 \times 16$ & 6 & 13 & 16 & 3.5 & 12.0 & 1.50 & 0.32 & 0.3 & 0.3 & 0.2 \\
\hline $6 \times 16 \times 20$ & 6 & 16 & 20 & 4 & 14.5 & 2.10 & 0.16 & 0.3 & 0.3 & 0.2 \\
\hline $6 \times 18 \times 22$ & 6 & 18 & 22 & 5 & 16.7 & 1.93 & 0.45 & 0.3 & 0.3 & 0.2 \\
\hline $6 \times 21 \times 25$ & 6 & 21 & 25 & 5 & 19.5 & 1.95 & 1.95 & 0.3 & 0.3 & 0.2 \\
\hline $6 \times 23 \times 28$ & 6 & 23 & 28 & 6 & 21.3 & 2.30 & 1.34 & 0.3 & 0.3 & 0.2 \\
\hline $6 \times 26 \times 32$ & 6 & 26 & 32 & 6 & 23.4 & 2.94 & 1.65 & 0.4 & 0.4 & 0.3 \\
\hline $6 \times 28 \times 34$ & 6 & 28 & 34 & 7 & 25.9 & 2.94 & 1.70 & 0.4 & 0.4 & 0.3 \\
\hline $8 \times 32 \times 38$ & 8 & 32 & 38 & 6 & 29.4 & 3.30 & 0.15 & 0.4 & 0.4 & 0.3 \\
\hline $8 \times 36 \times 42$ & 8 & 36 & 42 & 7 & 33.5 & 3.01 & 1.02 & 0.4 & 0.4 & 0.3 \\
\hline
\end{tabular}

From Table 2.2 and Unit 2.2 we find that the diameter of the coupling rod to be used is:

$\mathrm{D}=25 \mathrm{~mm}$. Table $2.2^{[5]}$ gives the following dimensions for the spline profile:

a) No. of splines $\mathrm{N}=6$

b) Minor diameter $d=21 \mathrm{~mm}$

c) Major diameter $\mathrm{D}=25 \mathrm{~mm}$

d) Width $\mathrm{B}=5 \mathrm{~mm}$

e) Tolerance $\mathrm{d} 1 *($ Min $)=19.5 \mathrm{~mm}$

$\mathrm{e}^{*}(\operatorname{Max})=1.95 \mathrm{~mm}$

$\mathrm{f}^{*}=1.95 \mathrm{~mm}$

$\mathrm{g}(\operatorname{Max})=0.3$

$$
\begin{aligned}
& \mathrm{k}(\operatorname{Max})=0.3 \\
& \mathrm{r}(\operatorname{Max})=0.2 \mathrm{~mm}
\end{aligned}
$$

f) Engaged length of the spline:

From Eqn. (2.1) we have;

$$
l=\frac{2 T}{p_{b} h N(D-h)}
$$

Where, $\mathrm{T}=7.003 \mathrm{~N}-\mathrm{m}=7003 \mathrm{~N}-\mathrm{mm}$

$p b=7 \mathrm{MN} / \mathrm{m}^{2}=7 \mathrm{~N} / \mathrm{mm}^{2}$

$\mathrm{h}=(D-d) / 2=2 \mathrm{~mm}$

$$
\mathrm{N}=6
$$

$\mathrm{D}=25 \mathrm{~mm}$

$\therefore l=7.249 \mathrm{~mm}$

$\approx 8 \mathrm{~mm}$

Therefore, the minimum engaged length of the splines should be greater than $8 \mathrm{~mm}$

\subsection{Recommended Dimensions of Bearings}

A bearing is a mechanical element that permits relative motion between two parts, such as the shaft and the housing, with minimum friction. The function of the bearing are as follows:

(i) The bearing ensures free rotation of the shaft or the axle with minimum friction

(ii) The bearing supports the shaft or the axle and holds it in correct position

(iii) The bearing takes up the forces that act on the shaft or the axle and transmits them to the frame or foundation

The appropriate type of bearing (radial, angular contact or thrust) is determined by the direction of the load which will act on the bearing, while the choice of the appropriate sliding contact surface combination is primarily determined by the way in which the load acts (constant or alternating direction) . Radial load - When the load is purely or predominantly radial, a radial spherical plain bearing should be selected. Axial load - When

\begin{tabular}{|c|c|c|c|c|c|c|c|c|c|}
\hline \multicolumn{10}{|c|}{ Table 2.3 SKF Bearings } \\
\hline \multirow{2}{*}{$\begin{array}{l}\text { Bearing No. } \\
\text { (SKF) }\end{array}$} & \multirow{2}{*}{$\begin{array}{l}\mathrm{d} \\
\mathrm{mm}\end{array}$} & \multirow{2}{*}{$\begin{array}{l}\mathrm{D} \\
\mathrm{mm}\end{array}$} & \multirow{2}{*}{$\begin{array}{l}\mathrm{B} \\
\mathrm{mm}\end{array}$} & \multirow{2}{*}{$\begin{array}{l}\mathrm{r} \\
\mathrm{mm}\end{array}$} & \multirow{2}{*}{$\begin{array}{l}\mathrm{r} 1 \\
\mathrm{~mm}\end{array}$} & \multirow{2}{*}{$\begin{array}{l}\mathrm{F} \\
\mathrm{mm}\end{array}$} & \multicolumn{2}{|c|}{ Basic capacity, $N^{*}$} & \multirow{2}{*}{$\begin{array}{l}\text { Max. permissible } \\
\text { speed rev/min }\end{array}$} \\
\hline & & & & & & & Static $(\mathrm{C} 0)$ & Dynamic $(\mathrm{C})$ & \\
\hline NU 2205 & 25 & 52 & 18 & 1.5 & 1.0 & 32 & 11030 & 15790 & 13000 \\
\hline 2206 & 30 & 62 & 20 & 1.5 & 1.0 & 38.5 & 16970 & 23140 & 13000 \\
\hline
\end{tabular}
the load is purely or predominantly axial then the choice should be a spherical plain thrust bearing. Combined load - When the load is made up of radial and axial components which are almost equal in magnitude, an angular contact spherical plain bearing should be chosen. 


\begin{tabular}{|l|l|l|l|l|l|l|l|l|l|}
\hline 2207 & 35 & 72 & 23 & 2.0 & 1.0 & 43.8 & 27655 & 35600 & 10000 \\
\hline NU 2208 & 40 & 80 & 23 & 2.0 & 2.0 & 50 & 32750 & 40700 & 10000 \\
\hline 2209 & 45 & 85 & 23 & 2.0 & 2.0 & 55 & 35600 & 43640 & 8000 \\
\hline 2210 & 50 & 90 & 23 & 2.0 & 2.0 & 60.4 & 38540 & 45500 & 8000 \\
\hline NU 2211 & 55 & 100 & 25 & 2.5 & 2.0 & 66.5 & 45500 & 52560 & 8000 \\
\hline 2212 & 60 & 110 & 28 & 2.5 & 2.5 & 73.6 & 59820 & 69630 & 6000 \\
\hline 2213 & 65 & 120 & 31 & 2.5 & 2.5 & 79.6 & 74040 & 81640 & 6000 \\
\hline NU 2214 & 70 & 125 & 31 & 2.5 & 2.5 & 84.5 & 78450 & 85910 & 5000 \\
\hline 2215 & 75 & 130 & 31 & 2.5 & 2.5 & 88.5 & 84730 & 96350 & 5000 \\
\hline 2216 & 80 & 135 & 33 & 3.0 & 3.0 & 95.3 & 98070 & 109340 & 5000 \\
\hline NU 2217 & 85 & 150 & 36 & 3.0 & 3.0 & 101.8 & 117680 & 12700 & 4000 \\
\hline 2218 & 90 & 160 & 40 & 3.0 & 3.0 & 107 & 135820 & 140235 & 4000 \\
\hline 2219 & 95 & 170 & 43 & 3.5 & 3.5 & 113.5 & 160340 & 173580 & 4000 \\
\hline
\end{tabular}

To satisfy our requirements, we select SKF bearing NU2207 from Table 2.3 $3^{[5]}$

\subsection{Recommended Dimensions of Universal Joint}

The universal joint is considered to be one of the oldest of all flexible couplings. It is commonly known for its use on automobiles and trucks. A universal joint in its simplest form consists of two shaft yokes at right angles to each other and a four point cross which connects the yokes. The cross rides inside the bearing cap assemblies, which are pressed into the yoke eyes. Universal joints have several unique features that make them ideal for a variety of applications. Universal joints are selected for size on the basis of the torque to be transmitted, the speed of rotation and the operating angle. These variables give rise to a performance chart on which the values can be read off and a suitable joint selected. A Universal joint works harder as the operating angle increases. The larger the operating angle, the lower the torque or the speed at which it can be transmitted, or both. In selecting the best type of universal joint for a given application, the intended duty and life requirement are the determining factors. High speeds and/or operating angles are best handled by Universal joints fitted with roller bearings.

Cardan single joints with needle bearing are used for transferring speeds. They have a minimal clearance and are maintenance free. Max. Transferable torque (Nm) at 150 r.p.m.; operation angle $\alpha<5^{\circ}$.

To satisfy our requirements, we select Norelem Cardan Joint 23406-12056 $6^{[7]}$ from Table $2.4^{[7]}$
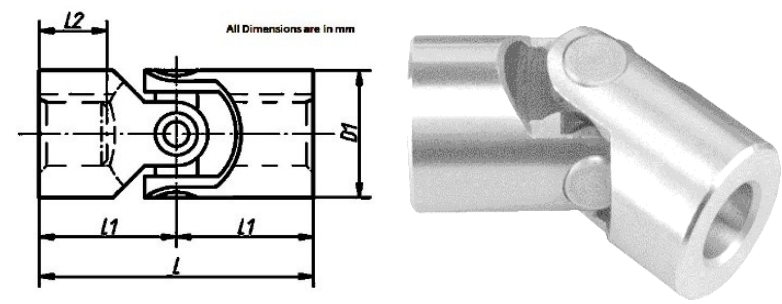

Figure 2.3 Cardan Joint

The selected Cardan joint has following specifications:

$\mathrm{D}=12 \mathrm{~mm} ; \mathrm{D}_{1}=25 \mathrm{~mm} ; \mathrm{L}=56 \mathrm{~mm} ; \mathrm{L}_{1}=28 \mathrm{~mm} ; \mathrm{L}_{2}=14 \mathrm{~mm} ; \mathrm{B}=4 \mathrm{~mm} ; \mathrm{T}=13.8 \mathrm{~mm}$; Max. Torque $\mathrm{Nm}=10$; Static fracture torque in $\mathrm{Nm}=80$; Approx. weight $\mathrm{kg}=0.085$

\begin{tabular}{|l|l|l|l|l|l|l|l|l|l|l|l|}
\hline \multicolumn{10}{|c|}{ Table 2.4 Norelem Cardan Joints } \\
\hline $\begin{array}{l}\text { Order No. } \\
\text { Locating hole } \\
\text { without slot }\end{array}$ & $\begin{array}{l}\text { Order No. Locating } \\
\text { hole } \\
\text { with slot }\end{array}$ & D & D1 & L & L1 & L2 & B & T & $\begin{array}{l}\text { Max. } \\
\text { torque } \\
\text { Nm }\end{array}$ & $\begin{array}{l}\text { static } \\
\text { fracture } \\
\text { torque in } \\
\text { Nm }\end{array}$ & $\begin{array}{l}\text { Approx. } \\
\text { weight } \\
\text { kg }\end{array}$ \\
\hline $23406-10048$ & $23406-110048$ & 10 & 20 & 48 & 24 & $12^{*}$ & 3 & 11,4 & 10 & 80 & 0,085 \\
\hline $23406-12056$ & $23406-112056$ & 12 & 25 & 56 & 28 & $14^{*}$ & 4 & 13,8 & 16 & 120 & 0,130 \\
\hline $23406-16068$ & $23406-116068$ & 16 & 32 & 68 & 34 & $16^{*}$ & 5 & 18,3 & 35 & 250 & 0,235 \\
\hline $23406-20082$ & $23406-120082$ & 20 & 40 & 82 & 41 & $20^{*}$ & 6 & 22,8 & 80 & 500 & 0,455 \\
\hline $23406-25104$ & $23406-125104$ & 25 & 50 & 104 & 52 & $25^{*}$ & 8 & 28,3 & 130 & 800 & 0,975 \\
\hline $23406-30166$ & $23406-130166$ & 30 & 63 & 166 & 83 & $38^{*}$ & 8 & 33,3 & 240 & 1500 & 2,850 \\
\hline
\end{tabular}

\section{Calculations}

\subsection{Capacity:}

The tonnage capacity of Screw Conveyor, "Q" in tons/hour is given by:

$Q=V_{Y}=\frac{\pi D^{2}}{4} \mathrm{SN} \phi Y C \times 60$ tons $/ \mathrm{hr}$ $(2.2 .1)^{[2]}$ 
Where,

$\mathrm{V}=$ volumetric capacity, $\mathrm{m}^{3}$ per hour

$\gamma=$ bulk density of material, tons per $\mathrm{m}^{3}$

$\mathrm{D}=$ screw diameter, $\mathrm{m}$

$\mathrm{S}=$ screw pitch, $\mathrm{m}$

$\mathrm{N}=$ rotational speed, $\mathrm{rpm}$

$\phi=$ loading efficiency of the vertical cross sectional area

$\mathrm{C}=$ factor depending on inclination of conveyor

$\phi$ varies with flow ability of the material as under:

\begin{tabular}{|l|l|}
\hline \multicolumn{2}{|c|}{ Table 3.1 Loading Efficiency } \\
\hline Material Characteristics & Value of $\phi$ \\
\hline Slow flowing, abrasive (clinker, ash) & 0.125 \\
\hline Slow flowing, mild abrasive & 0.25 \\
\hline Free flowing, mild abrasive (sand) & 0.32 \\
\hline Free flowing, non-abrasive (grain) & 0.4 \\
\hline
\end{tabular}

For free flowing, mildly abrasive sand, which is our material to be conveyed has value of $\phi=0.32$ Value of ' $C$ ' varying with inclination angle $\beta$ is related as shown in following chart ${ }^{[1]}$.

\begin{tabular}{|l|l|l|l|l|l|}
\hline \multicolumn{7}{|c|}{ Table 3.2 Factor Depending On Inclination } \\
\hline$\beta$ & $0^{\circ}$ & $5^{\circ}$ & $10^{\circ}$ & $15^{\circ}$ & $20^{\circ}$ \\
\hline $\mathrm{C}$ & 1.0 & 0.9 & 0.8 & 0.7 & 0.65 \\
\hline
\end{tabular}

The screw diameter and speeds vary widely depending on the designed capacity of the conveyor and the nature of the material handled. However, the speed is generally reduced as the diameter goes up, as shown in Table 2.1.3(a) ${ }^{[1]}$.

\begin{tabular}{|l|l|l|l|l|l|l|l|}
\hline \multicolumn{7}{|c|}{ Table 3.3 Permissible Speeds For Screw Conveyor } \\
\hline Screw Diameter (mm) & 160 & 200 & 250 & 300 & 400 & 500 & 630 \\
\hline Maximum R.P.M. & 150 & 150 & 120 & 120 & 95 & 90 & 75 \\
\hline Minimum R.P.M & 25 & 25 & 20 & 20 & 20 & 15 & 10 \\
\hline
\end{tabular}

We can see that the maximum rpm for a $160 \mathrm{~mm}$ diameter screw is $150 \mathrm{rpm}$. As a $100 \mathrm{~mm}$ diameter is smaller, therefore 150rpm will certainly be within its permissible range. Therefore it is safe to assume 150rpm of rotating speed for our model.

We have,

$\mathrm{N}=150 \mathrm{rpm}$,

$\Phi=0.32$

$\gamma=1.6$

$\mathrm{C}=0.8$ (for inclination at $10^{\circ}$ )

Higher the inclination, lesser the value of C. Since the steepest segment of our model is at $10^{\circ}$. Thus, the maximum capacity of the conveyor is decided by it.

And from Unit 2.1.3, we have,

$\mathrm{D}=100 \mathrm{~mm}$,

$\mathrm{S}=80 \mathrm{~mm}$,

$\therefore \mathrm{Q}=2.316$ tons/hour

\subsection{Power Requirements:}

IS1296:1990 "Determination of Power Requirement of Screw Feeder-General Requirements ${ }^{[1]}$ has recommended the method for calculation of power requirement of a screw conveyor.

During Power of a loaded screw conveyor may be estimated by formula

$$
\mathrm{P}=\mathrm{P}_{\mathrm{H}}+\mathrm{P}_{\mathrm{N}}+\mathrm{P}_{\mathrm{St}}
$$

Where,

$\mathrm{P}_{\mathrm{H}}=$ Power necessary for conveying material

$\mathrm{P}_{\mathrm{N}}=$ Driving Power of Conveyor at no load

$\mathrm{P}_{\mathrm{St}}=$ Power requirement for inclination at the conveyor

\subsubsection{Power necessary for conveying material}

$P_{H}=\frac{\mathrm{Q} \mathrm{L} \lambda}{367}, \mathrm{KW}$ 
Where,

$\mathrm{Q}=$ Mass flow rate in tonnes/hour

$\mathrm{L}=$ Length of material movement in conveyor in $\mathrm{m}$

$\lambda=$ Progress resistance coefficient (friction coefficient)

$=4$ for sand.

\subsubsection{Drive power at no load:}

$\mathrm{P}_{\mathrm{N}}$ is proportional to the screw diameter and total length of the screw.

$P_{N}=\frac{D L}{20}, K W$.

Where,

$\mathrm{D}=$ Nominal Screw diameter, $\mathrm{m}$

$\mathrm{L}=$ Length of Screw, $\mathrm{m}$

\subsubsection{Power requirement for inclination at the conveyor:}

$\mathrm{P}_{\mathrm{St}}$ is the product of the mass flow rate and height to which the material is being conveyed.

$P_{S t}=\frac{Q H}{367}, \mathrm{KW}$

Where,

$\mathrm{Q}=$ Mass flow rate in tonnes/hour

$\mathrm{H}=$ Height of the inclination in $\mathrm{m}$

I. Considering First Body of Screw Conveyor at 0 Degree Inclination:

Here,

$\mathrm{Q}=2.316$ tons/hour,

$\mathrm{L}=1.5 \mathrm{~m}$,

$\lambda=$ Progress resistance coefficient (friction coefficient)

$=4$ for sand. $\therefore \mathrm{P}_{\mathrm{H}}=0.0378 \mathrm{KW}$

And,

$\mathrm{D}=100 \mathrm{~mm},=0.1 \mathrm{~m}$

$\mathrm{L}=1.5 \mathrm{~m}$.

$\therefore \mathrm{P}_{\mathrm{N}}=7.5 \times 10-3 \mathrm{KW}$

$\therefore$ Power needed for First Screw Conveyor Body $\quad \mathrm{P}_{1}=\mathrm{P}_{\mathrm{H}}+\mathrm{P}_{\mathrm{N}}$

$=0.0453 \mathrm{KW}$

II. Considering Second Body of Screw Conveyor at 5 Degree Inclination:

Here,

$\mathrm{Q}=2.316$ tons $/ \mathrm{hr}$.

$\mathrm{L}=1 \mathrm{~m}$,

$\lambda=$ Progress resistance coefficient (friction coefficient)

$=4$ for sand. $\therefore \mathrm{P}_{\mathrm{H}}=0.0252 \mathrm{KW}$

And,

$\mathrm{D}=100 \mathrm{~mm}=0.1 \mathrm{~m}$,

$\mathrm{L}=1 \mathrm{~m}$,

$\therefore \mathrm{P}_{\mathrm{N}}=5 \times 10-3 \mathrm{KW}$

And,

$\mathrm{Q}=2.316$ tons/hour,

$\mathrm{H}=\mathrm{L} \times \operatorname{Cos}\left(5^{\circ}\right)$

$\therefore \mathrm{P}_{\mathrm{St}}=6.286 \times 10-3 \mathrm{KW}$

$\therefore$ Power needed for Second Screw Conveyor Body

$$
\begin{aligned}
\mathrm{P} & =\mathrm{P}_{\mathrm{H}}+\mathrm{P}_{\mathrm{N}}+\mathrm{P}_{\mathrm{St}} \\
& =0.0362 \mathrm{KW}
\end{aligned}
$$

III. Considering Third Body of Screw Conveyor at 10 Degree Inclination:

Here,

$\mathrm{Q}=2.316$ tons $/ \mathrm{hr}$.

$\mathrm{L}=0.5 \mathrm{~m}$,

$\lambda=$ Progress resistance coefficient (friction coefficient)

$=4$ for sand. $\therefore \mathrm{PH}=0.0126 \mathrm{KW}$ 
And,

$$
\begin{aligned}
& \mathrm{D}=100 \mathrm{~mm}=0.1 \mathrm{~m}, \\
& \mathrm{~L}=0.5 \mathrm{~m},
\end{aligned}
$$

$\therefore \mathrm{PN}=2.5 \times 10-3 \mathrm{KW}$

And, $\quad \mathrm{Q}=2.316$ tons $/ \mathrm{hr}$.

$\mathrm{H}=\mathrm{L} \times \operatorname{Cos}\left(10^{\circ}\right)$

$\therefore \mathrm{P}_{\mathrm{St}}=3.107 \times 10-3 \mathrm{KW}$

$\therefore$ Power needed for Third Screw Conveyor Body

$\mathrm{P}=\mathrm{P}_{\mathrm{H}}+\mathrm{P}_{\mathrm{N}}+\mathrm{P}_{\mathrm{St}}$

$=0.0182 \mathrm{KW}$

Total Power Required,

$\mathrm{P}=P_{1}+P_{2}+P_{3}$

$$
=0.0997 \mathrm{KW}
$$

$\approx 0.1 \mathrm{KW} \approx 100$ watt

This gives us the minimum power needed to rotate the screw conveyor at max load condition. Only a motor of power 100 watts or higher can be used to power this screw conveyor..

\section{Cad Parts For Screw Conveyor Assembly}
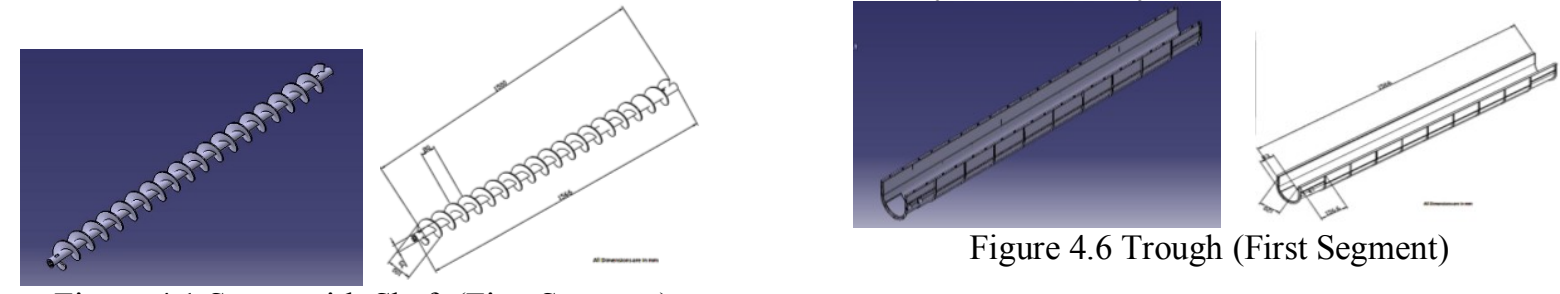

Figure 4.6 Trough (First Segment)

Figure 4.1 Screw with Shaft (First Segment)
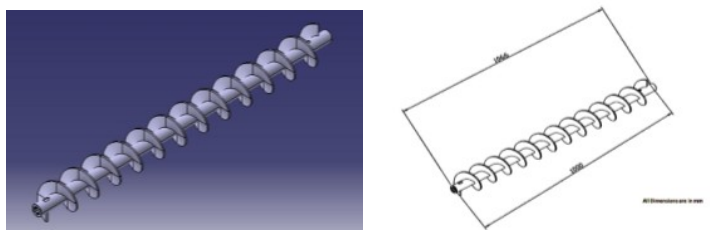

Figure 4.2 Screw with Shaft (Second Segment)
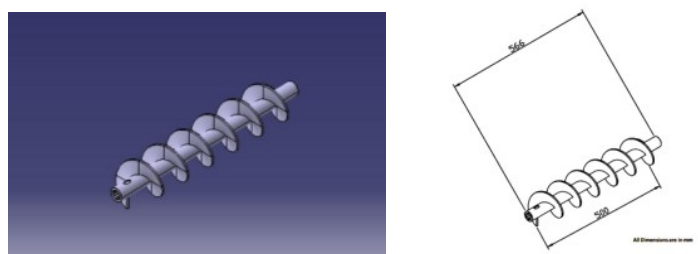

Figure 4.3 Screw with shaft (Third Segment)

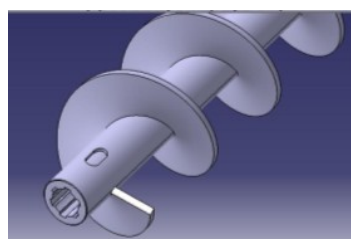

Figure 4.4 Inside Spline and Inserted Body
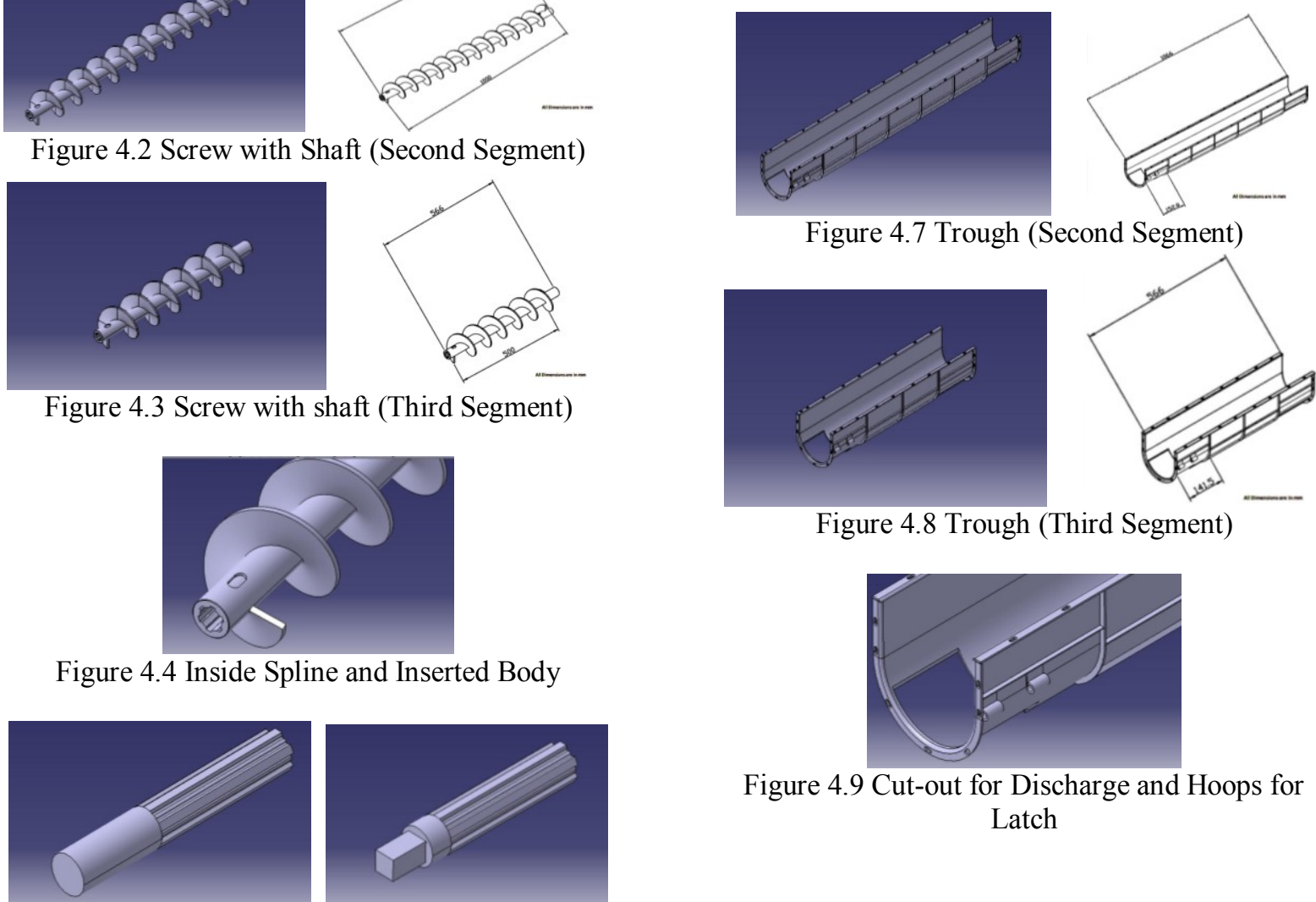

Figure 4.7 Trough (Second Segment)
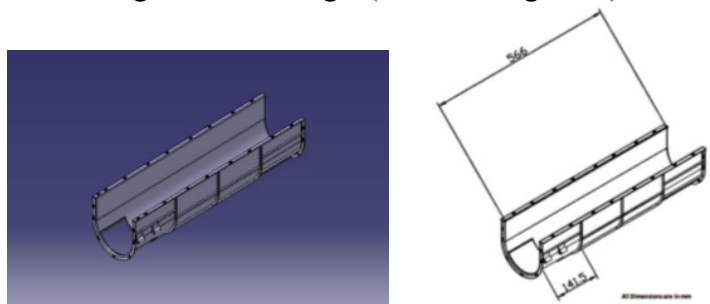

Figure 4.8 Trough (Third Segment)

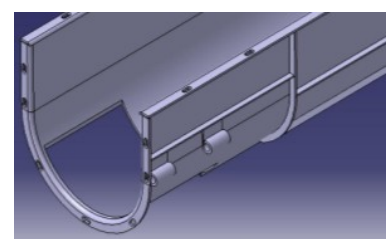

Figure 4.9 Cut-out for Discharge and Hoops for Latch

Figure 4.5 Coupling Rod (Driver and Intermediate) 


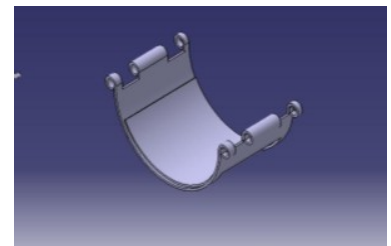

Figure 4.10 Cover for Mix and Match Use

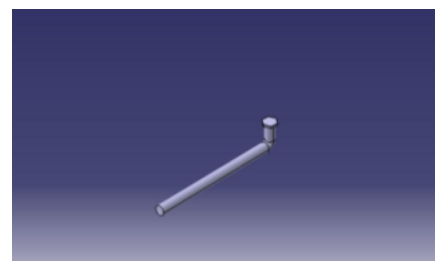

Figure 4.11 Latch

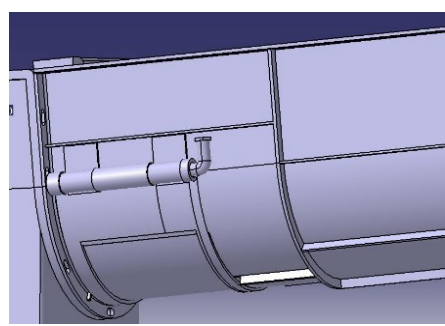

Figure 4.12 Assembled View of Trough with Cover and Latch
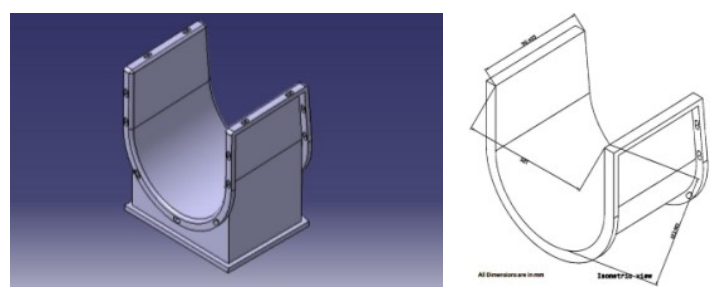

Figure 4.13 Attachment for Joining Two Segments at 5 Degree Incline

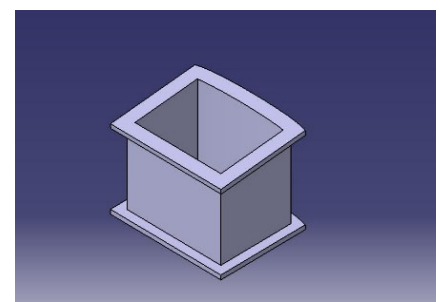

Figure 4.14 Support for Attachment Between Second and Third Segment

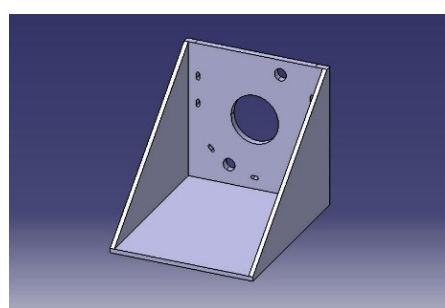

Figure 4.15 Trough End Support

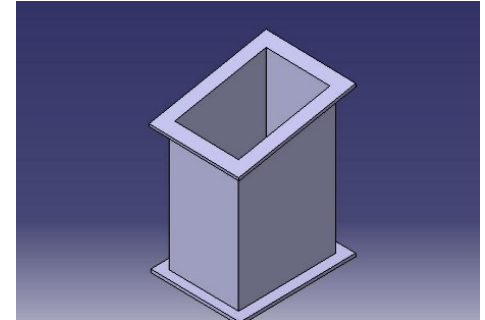

Figure 4.16 Support for Trough End Attachment

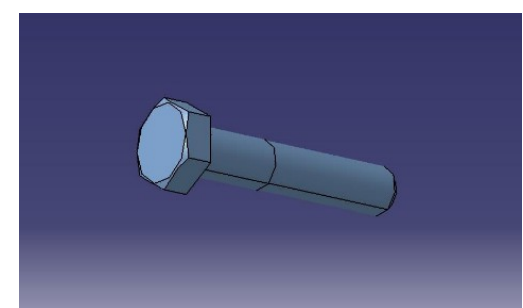

Figure 4.17 ISO 4014 Bolt M5×25 Steel Grade A Hexagon Head

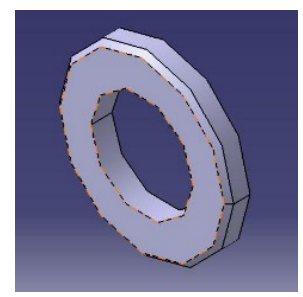

Figure 4.18 ISO 7092 Washer $5 \times 9$ Steel Grade A Plain Small Series

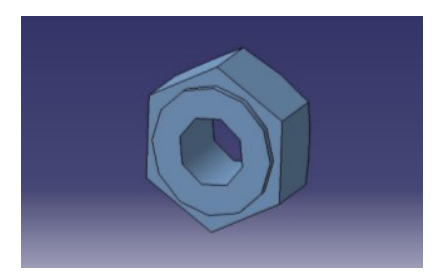

Figure 4.19 ISO 4032 Nut M6 Steel Grade A Washer Faced Hexagon Head

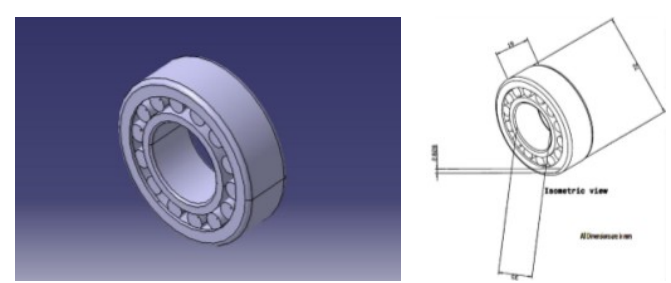

Figure 4.20 SKF NU2207 Roller Bearing

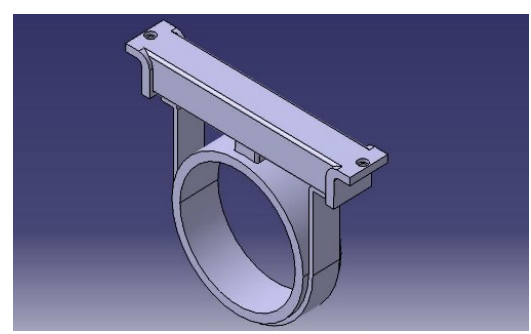

Figure 4.21 Bearing Hangar 


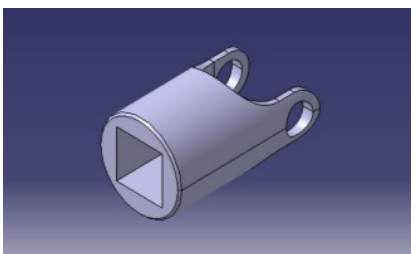

Figure 4.22 Joint
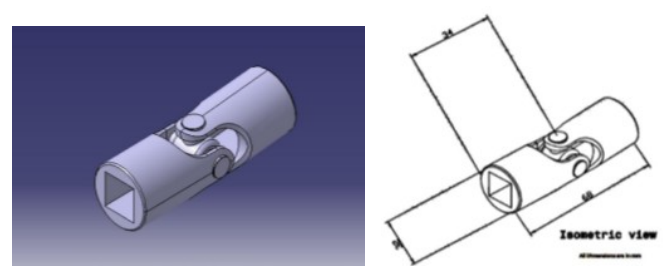

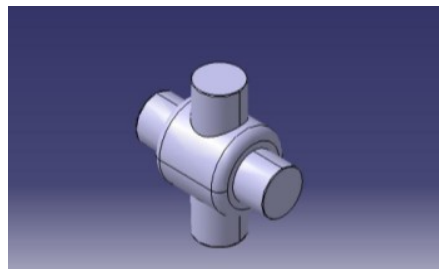

Figure 4.23 Cross

Figure 4.24 Assembled View of Cardan Joint

\section{Results And Conclusions}

We have designed a CAD model of a segmented screw conveyor which successfully demonstrates the use of universal joints to make a semi flexible screw conveyor. The following parts have been successfully designed in accordance to their selection criteria: The designed Screw Conveyor has the following the specifications:

Capacity $=2.361$ tons/hour at $150 \mathrm{rpm}$

Power required $=100$ watt minimum

Material handled $=$ Dry sand

Length of Material travel $=3.4 \mathrm{~m}$

Height of Material travel $=0.36 \mathrm{~m}$

Screw diameter $(D)=100 \mathrm{~mm}$

Flight thickness $=5 \mathrm{~mm}$

Shaft diameter $(\mathrm{d})=35 \mathrm{~mm}$

Coupling shaft diameter $=25 \mathrm{~mm}$

Through width $(\mathrm{C})=120 \mathrm{~mm}$

Through height (a) $=63 \mathrm{~mm}$

The developed CAD model consists of the following parts:

\begin{tabular}{|l|l|l|}
\hline \multicolumn{2}{|c|}{ Table 5.1 Parts Developed And Applied } \\
\hline PART & SPECIFICATIONS & QUANTITY \\
\hline Helical screw with shaft & $1 . \mathrm{L}=1566 \mathrm{~mm}$ & 1 \\
& $2 . \mathrm{L}=1066 \mathrm{~mm}$ & 1 \\
& $3 . \mathrm{L}=566 \mathrm{~mm}$ & 1 \\
\hline Trough & $1 . \mathrm{L}=1566 \mathrm{~mm}$ & 1 \\
& $2 . \mathrm{L}=1066 \mathrm{~mm}$ & 1 \\
& $3 . \mathrm{L}=566 \mathrm{~mm}$ & 1 \\
\hline Coupling Rod & 1. L=160mm (Driver) & 1 \\
& 2. L=141.5mm (Intermediate) & 1 \\
\hline Bearing & SKF NU2207 (Roller Bearings) & 6 \\
\hline Cardan Joint & Cardan Joint 23406-12056 & 2 \\
\hline Bearing Hanger & For SKF NU2207 & 4 \\
\hline Flanged housing & For SKF NU2207 & 2 \\
\hline Attachment & For inclined support to segments & 2 \\
\hline Attachment support & For support to attachment at second linkage & 1 \\
\hline End Attachment & Attachment at trough ends & 2 \\
\hline End Attachment support & Support for end attachment at inclined end & 1 \\
\hline Cover Bottom & For intermediate troughs & 2 \\
\hline Latch & To assemble cover bottom with troughs & 4 \\
\hline Hexagonal bolts & ISO 4014 Bolt M5X25 Steel grade A Hexagon Head & 36 \\
\hline Washer & ISO 4014 Bolt M12x50 Steel grade A Hexagon Head & 4 \\
\hline Nuts & ISO 7092 Washer 5x9 Steel grade A Plain Small Series ISO 7092 & 36 \\
& Washer 12x20 Steel grade A Plain Small Series & 4 \\
\hline
\end{tabular}




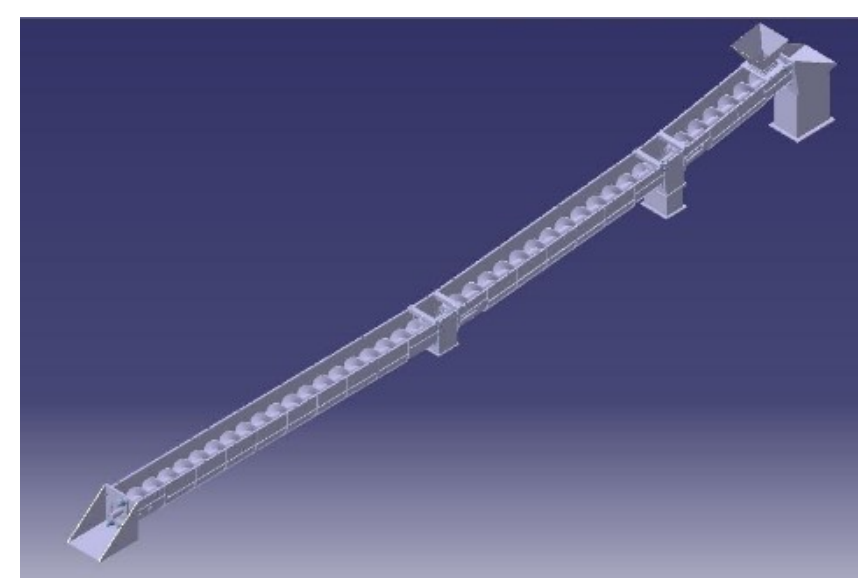

Figure 5.1 Semi Flexible Screw Conveyor Assembly

We have successfully developed and assembled the CAD model of the Semi-Flexible Screw Conveyor. This proves that the concept of using universal joints, with standard conventional screw conveyor parts, provides the user a certain degree of flexibility example variable length traverse and variable inclination in both vertical and horizontal planes. This model supersedes current flexible models of the screw conveyor in the terms of cost and convenience as it uses standard conventional specifications and material as opposed to the special and expensive materials and techniques used in others.

\section{Acknowledgements}

We take this opportunity to sincerely express our thanks and deep gratitude to all who extended their whole hearted co-operation, opinion and gracious hospitality to us in completing this work. It is our immense pleasure to have worked under the guidance of Assistant Professor Santanu Chakarborthy. We are very grateful to him for being incredibly supportive throughout the work and his exhaustive guidance and patience he has while listening my approaches. We are very thankful to Prof. (Dr.) B. B. Pradhan, Head of Department, Mechanical Engineering, Sikkim Manipal Institute of Technology.We owe our greatest debt to The Director Col. (Dr.) Sadasivan Thekkey Veetil (Retd.) Sikkim Manipal Institute of Technology for his constant support and encouragement to complete the project work. And, lastly to our families for supporting our endeavors.

\section{Journal Papers:}

\section{References}

[1]. Uematsu T., Nakamura S., Hino, Y. and Suyama, 'A study of the screw conveyor 'Trans. JSME, 26(162), 180-186. (1960).

[2]. Chris Rorres "The turn of the screw: Optimal design of an Archimedes Screw", Page: 72-80, Journal of Hydraulic Engineering / January 2000

\section{Books:}

[3]. Siddharta Ray, "Introduction to Materials Handling” New Age International (P) Ltd., 2008, pp. 112-118.

[4]. Don McGlinchey, "Bulk solids handling, equipment selection and operation” Blackwell Publishing Ltd., 2008, pp. 197-220.

[5]. Kevin Otto, Kristin Wood, "Product design-Techniques in Reverse engineering and New Product Development," Pearson Education Inc., 2001.

[6]. V.B Bhandari, "Design of machine elements" Tata McGraw-Hill, 2007.

[7]. K. Mahadevan, K. Balaveera Reddy, "Design data handbook for mechanical engineers in SI and Metric units," CBS Publishers and Distributers, Fourth Edition., February 2013.

[8]. $\quad$ Norelem Catalogue, "The big green book," pp. 971

[9]. Alan W. Roberts "Design considerations and performance evaluation of screw conveyors."

\section{Theses:}

[10]. Marion H Fennimore, Ivan J Stephenson, "Flexible screw conveyor" US2830695 A, Apr 15, 1958. 